\title{
The inhibitory activity of herbal medicines on the keys enzymes and steps related to carbohydrate and lipid digestion
}

Weerachat Sompong ${ }^{1}$, Nuttapat Muangngam², Artitaya Kongpatpharnich², Chadakarn Manacharoenlarp², Chanatkarn Amorworasin², Tanyawan Suantawee ${ }^{3}$, Thavaree Thilavech ${ }^{1}$ and Sirichai Adisakwattana ${ }^{1 *}$

\begin{abstract}
Background: Obesity and overweight are consistently associated with metabolic disorders including hyperglycemia and hyperlipidemia. Herbal medicines have been currently suggested as an alternative source of potentially useful antihyperglycemic, antihyperlipidemic, antioxidant activities. The objective of this study was to assess the in vitro inhibitory effects of eleven herbal medicines on carbohydrate and lipid digestive enzymes and the key steps of lipid digestion including the inhibition of micelle formation and the ability to bind bile acid. In addition, antioxidant activity of herbal medicines was also investigated.
\end{abstract}

Methods: a-Glucosidase, pancreatic a-amylase, pancreatic lipase, and pancreatic cholesterol esterase inhibitory activities of aqueous extract of herbal medicines were measured using the enzymatic colorimetric assay. The formation of cholesterol micelles was determined using the cholesterol assay kit. The bile acid binding was measured using the colorimetric assay. Antioxidant activities were assessed by using four methods including Trolox equivalent antioxidant capacity (TEAC), oxygen radical absorbance capacity ORAC), superoxide radical scavenging activity (SRSA), and hydroxyl radical scavenging activity (HRSA).

Results: The extracts $(1 \mathrm{mg} / \mathrm{mL})$ markedly inhibited intestinal maltase (5.16-44.33\%), sucrase (1.25-45.86 \%), pancreatic a-amylase (1.75-12.53\%), pancreatic lipase (21.42-85.93\%), and pancreatic cholesterol esterase (2.92-53.35\%). The results showed that all extracts exhibited the inhibitory activity against pancreatic lipase with the $\mathrm{IC}_{50}$ values ranging from 0.015 to $4.259 \mathrm{mg} / \mathrm{mL}$. In addition, the incorporation of cholesterol into micelles was inhibited by the extracts (6.64-33.74 \%). The extracts also bound glycodeoxycholic acid (9.9-15.08 \%), taurodeoxycholic acid (12.55-18.18\%), and taurocholic acid (11.91-18.4\%). Furthermore, the extracts possessed various antioxidant activities including the TEAC values $(0.50-4.70 \mu \mathrm{mol}$ trolox/mg dried extract), the ORAC values (9.14-44.41 $\mathrm{mmol}$ trolox/mg dried extract), the SRSA (0.31 - $18.82 \mathrm{mg}$ trolox/mg dried extract), and the HRSA (0.05-2.29 mg trolox/mg dried extract). The findings indicated that Syzygium aromaticum, Phyllanthus amarus, Thunbergia laurifolia were the effective promising antihyperglycemic and antihyperlipidemic agents. Statistical analysis demonstrated strong positive significant correlations between the contents of phenolic compounds and $\%$ inhibition of pancreatic lipase $(r=0.885, p<0.001)$, \% inhibition of pancreatic cholesterol esterase $(r=0.761$, $p<0.001)$, and the TEAC value $(r=0.840, p<0.001)$. Furthermore, there was a strongly positive correlation between the TEAC value and $\%$ inhibition of pancreatic cholesterol esterase $(r=0.851, p<0.001)$ and $\%$ inhibition of pancreatic lipase $(r=0.755, p<0.001)$.

\footnotetext{
*Correspondence: Sirichai.a@chula.ac.th

'Department of Nutrition and Dietetics, Faculty of Allied Health Sciences,

Chulalongkorn University, Bangkok 10330, Thailand

Full list of author information is available at the end of the article
} 
(Continued from previous page)

Conclusions: Three herbal medicines including Syzygium aromaticum, Thunbergia laurifolia, and Phyllanthus amarus markedly inhibited the intestinal a-glucosidase, pancreatic a-amylase, pancreatic lipase, and pancreatic cholesterol esterase. They also reduced formation of cholesterol micelle and bound bile acid. The findings indicate that these herbal medicines might be a promising agent for antihyperglycemic, antihyperlipidemic, and antioxidant activities.

Keywords: Herbal medicines, Antihyperglycemia, Antihyperlipidemia, Antioxidant

\section{Background}

The prevalence of obesity and overweight has dramatically increased worldwide due to a modern lifestyle and an increase of consumption of high-fat and highcarbohydrate diets [1]. Obesity and overweight are consistently associated with the elevation of blood glucose and lipid levels. Hyperglycemia and hyperlipidemia are major risk factors for developing chronic diseases such as diabetes mellitus and cardiovascular diseases [1]. One of the interesting strategies for the prevention of obesity is to reduce or slow dietary carbohydrate and fat digestion and absorption in the small intestine [2, 3 ]. The results from this action cause attenuated rises in postprandial hyperglycemia, hypertriacylglycerolemia and hypercholesterolemia, consequently, reduced risks of the progression of cardiovascular diseases and diabetes and its complications $[4,5]$. Additionally, consumption of carbohydrate- and fat-enriched foods results in a significant increase in postprandial glucose and oxidative stress by the formation of reactive oxygen species through several biochemical pathways [6]. Current evidence supports that the well-known $\alpha$-glucosidase inhibitors (acarbose and voglibose) and pancreatic lipase inhibitor (orlistat) are clinically used for treatment of hyperglycemia and hyperlipidemia $[7,8]$. In overweight and obese people, the suppression of postprandial glucose and lipid levels may reduce the incidence of developing diabetes and its complications [9]. However, they have been reported that use of these inhibitors is associated with unpleasant gastrointestinal side effects such as abdominal pain, flatulence, meteorism, and diarrhea $[10,11]$.

Nowadays, numerous herbal medicines have been reported as good sources of unique phytochemical compounds such as polyphenols and flavonoids. The scientists have investigated potential herbal medicines for the development of newer therapeutics for biologically active antioxidants, antihyperlipidemic and antihyperglycemic agents from natural resources, especially the reduction of carbohydrate and fat digestion and absorption [12, 13]. As described in Table 1, herbal medicines have been commonly used for the treatment of various diseases in the Ayurvedic system of Thai traditional medicine. Previous reports have shown the methylglyoxal-trapping abilities of herbal medicines and their inhibitory activities on the formation of protein glycation $[14,15]$. Nevertheless, studies addressing the inhibition of these herbal medicines on the key enzymes and steps of carbohydrate and lipid digestions remain unknown. Therefore, the present investigation was to evaluate the effects of eleven herbal medicines on the intestinal $\alpha$-glucosidases and pancreatic $\alpha$-amylase. Moreover, the study was also investigated the inhibition of pancreatic lipase and pancreatic cholesterol esterase activities as well as inhibiting formation of cholesterol micellization, and bile acid binding. Finally, eleven herbal medicines were elucidated their antioxidant activities including Trolox equivalent antioxidant capacity (TEAC), oxygen radical absorbance capacity (ORAC), hydroxyl radical scavenging activity (HRSA), and superoxide radical scavenging activity (SRSA).

\section{Methods \\ Chemicals}

Gallic acid, rat intestinal acetone powder, porcine pancreatic $\alpha$-amylase, 4-methylumbelliferone, glucose oxidase kits and 3,5-dinitrosalicylic acid $p$-nitrophenylbutylrate ( $p$ $\mathrm{NPB}$ ), oleic acid, phosphatidylcholine, glycodeoxycholic acid, taurodeoxycholic acid, taurocholic acid, porcine cholesterol esterase, porcine pancreatic lipase were purchased from Sigma-Aldrich Co. (St. Louis, MO, USA). Cholesterol test kits were purchased from HUMAN GmbH Co. (Wiesbaden, Germany). Total bile acid kit was purchased from Bio-Quant Co. (San Diego, CA, USA). All other chemical reagents used in this study were of analytical grade.

\section{Plant materials}

The plants were purchased from a specific herbal drugstore, Bangkok, Thailand. The plant authentication was performed according to our previous report [15]. The extraction of herbal medicines was done according to a previous report [15]. Briefly, the plants $(20 \mathrm{~g})$ were boiled in distilled water $(800 \mathrm{~mL})$ for $3 \mathrm{~h}$ at $95{ }^{\circ} \mathrm{C}$ before filtered through Whatman No. 1 filter paper. Thereafter, the extraction was lyophilized with a freeze drier. The lyophilized powder was stored at $4{ }^{\circ} \mathrm{C}$ in a dark bottle until analysis. The powder of extracts (final concentration: $1 \mathrm{mg} / \mathrm{mL}$ ) was resuspended in distilled water before experiments. 
Table 1 The list of plants was used of this study

\begin{tabular}{|c|c|c|c|c|}
\hline \\
\hline \multicolumn{5}{|l|}{ Scientific name } \\
\hline Rhinacanthus nasutus & Acanthaceae & Leaves & Rhinacanthin [34] & $\begin{array}{l}\text { Antidiabetes [35], antimicrobial [36], } \\
\text { antiproliferative [34] }\end{array}$ \\
\hline Cissus quadrangularis & Vitaceae & Aerial parts & Flavonoids, triterpenoids, tannins [37] & $\begin{array}{l}\text { Antidiabetes [37], hepatoprotective [38], } \\
\text { antiobesity [39], bone health [40] }\end{array}$ \\
\hline Syzygium aromaticum & Myrtaceae & Buds & $\begin{array}{l}\text { Eugenol (essential oil), flavonoids, aromatic } \\
\text { hydroxy acids, tannins [41], triterpenoids [25] }\end{array}$ & $\begin{array}{l}\text { Antioxidant [41], antiulcer [42], } \\
\text { immunomodulatory [43], } \\
\text { anticancer [44], antidiabetes [25] }\end{array}$ \\
\hline Acanthus ebracteatus & Acanthaceae & Leaves & Megastigmane, benzoxazinoids [45] & Antimicrobial [45], antitumor [46] \\
\hline Thunbergia laurifolia & Acanthaceae & Leaves & $\begin{array}{l}\text { Rosmarinic acid [47], polyphenols, } \\
\text { carotenoids, sterols [48] }\end{array}$ & $\begin{array}{l}\text { Antiinflammatory [47], antimutagenic [49], } \\
\text { antidiabetes [30], hepatoprotective [50], }\end{array}$ \\
\hline Phyllanthus amarus & Euphorbiaceae & Aerial parts & Triterpenoids, lignans [51] & $\begin{array}{l}\text { Immunosuppressive [52], antimicrobial, } \\
\text { antiinflammatory [53], antioxidant [54] }\end{array}$ \\
\hline Cassia alata & Leguminosae & Leaves & Antraquinones, flavonoids [55] & $\begin{array}{l}\text { Antioxidant, antiinflammatory [56], } \\
\text { antimicrobial [55] }\end{array}$ \\
\hline Pluchea indica & Asteraceae & Aerial parts & $\begin{array}{l}\text { Eudesmane, terpenoids, thiophene, } \\
\text { lignins, flavonoids [57] }\end{array}$ & $\begin{array}{l}\text { Antiinflammatory [57], antituberculosis [58], } \\
\text { antiulcer [59] }\end{array}$ \\
\hline Cryptolepis buchanani & Asclepiadaceae & Aerial parts & Nicotinoyl alkaloid, pyridine alkaloid [60] & Antiinflammatory [60] \\
\hline Derris scandens & Fabaceae & Aerial parts & Isoflavone, isoscandinone, scandenins $[61,62]$ & Antiinflammatory [61], antidiabetes [62] \\
\hline Schefflera leucantha & Araliaceae & Leaves & Steroids, terpenoids, flavonoids [63] & Antioxidant, antityrosinase, antimicrobial [63] \\
\hline
\end{tabular}

\section{Intestinal a-glucosidase inhibitory activity}

The intestinal $\alpha$-glucosidase inhibitory activity was determined according to a previous method [16]. Briefly, $100 \mathrm{mg}$ of rat intestinal acetone powder was homogenized in $3 \mathrm{~mL}$ of $0.9 \% \mathrm{NaCl}$ solution. The solution was centrifuged at $12,000 \mathrm{~g}$ for $30 \mathrm{~min}$ and then subjected to assay. The crude enzyme solution was incubated with $25 \mathrm{mM}$ maltose or $160 \mathrm{mM}$ sucrose together with various extracts in $0.1 \mathrm{M}$ phosphate buffer (PBS), $\mathrm{pH}$ 6.9. The reaction was incubated at $37{ }^{\circ} \mathrm{C}$ for $30 \mathrm{~min}$ (maltase assay) or $60 \mathrm{~min}$ (sucrase assay). Thereafter, the mixtures were suspended in boiling water for $10 \mathrm{~min}$ to stop the reaction. The concentrations of glucose released from the reaction mixtures were determined by glucose oxidase method with the absorbance at a wavelength of $450 \mathrm{~nm}$. Intestinal maltase and sucrase inhibitory activity was expressed as the percentage inhibition using the following formula:

$$
\% \text { Inhibition }=\frac{A b s_{\text {Control }}-A b s_{\text {Sample }}}{A b s_{\text {Control }}} \times 100
$$

Acarbose was used as positive control in this study.

\section{Pancreatic a-amylase inhibitory activity}

The pancreatic $\alpha$-amylase inhibition assay was done according to a previous method [16]. The various concentrations of the extracts were incubated with solution containing porcine pancreatic $\alpha$-amylase (3 units $/ \mathrm{mL}$ ), starch (1 g/L), and 0.1 M PBS, pH 6.9, for $10 \mathrm{~min}$, the reaction was then stopped by $1 \%$ dinitrosalicylic (DNS) reagent (3,5-dinitrosalicylic acid, $0.2 \%$ phenol, $0.05 \%$ $\mathrm{Na}_{2} \mathrm{SO}_{3}$ and $1 \% \mathrm{NaOH}$ in aqueous solution). After heating at $100{ }^{\circ} \mathrm{C}$ for $10 \mathrm{~min}, 40 \%$ potassium sodium tartarate solution was added to the mixtures to stabilize the color. After cooling to room temperature in a cold water bath, the absorbance was measured at $540 \mathrm{~nm}$ using a microplate reader.

$$
\% \text { Inhibition }=\frac{A b s_{\text {Control }}-A b s_{\text {Sample }}}{A b s_{\text {Control }}} \times 100
$$

Where $\mathrm{Abs}_{\text {Control }}$ was the absorbance without sample, $\mathrm{Abs}_{\text {sample }}$ was the absorbance of sample extract. Acarbose was used as positive control in this study.

\section{Pancreatic lipase inhibition}

Pancreatic lipase activity was done according to a previous method [17]. The sample solution was incubated with the pancreatic lipase solution $(12.5 \mathrm{U} / \mathrm{mL})$ and $0.05 \mathrm{mM}$ oleate ester of fluorescent 4-methylumbelliferone (4MUO) solution in $0.1 \mathrm{M}$ PBS, pH 6.9. After incubation at $37{ }^{\circ} \mathrm{C}$ for $20 \mathrm{~min}$, the reaction was terminated by $0.1 \mathrm{M}$ sodium citrate ( $\mathrm{pH} 4.2)$. The amount of 4-MUO released by lipase was determined using a fluorescence spectrophotometer at an excitation wavelength of $320 \mathrm{~nm}$ and an emission wavelength of $450 \mathrm{~nm}$. Orlistat was used as a positive control in this study. 


\section{Pancreatic cholesterol esterase inhibition}

The pancreatic cholesterol esterase inhibition was performed according a previously described method [17]. The extract was incubated with the mixtures containing $5.16 \mathrm{mM}$ taurocholic acid, $0.2 \mathrm{mM} p$-NPB in $100 \mathrm{mM}$ sodium phosphate buffer, $100 \mathrm{mM} \mathrm{NaCl}, \mathrm{pH}$ 7.0. After incubation with porcine pancreatic cholesterol esterase $(1 \mu \mathrm{g} / \mathrm{mL})$ for $5 \mathrm{~min}$ at room temperature, the mixtures were measured the absorbance at the wavelength of $405 \mathrm{~nm}$. Simvastatin was used as a positive control for this study.

\section{Cholesterol micellization}

Artificial micelles were prepared according to a previously described method [17]. In brief, the mixtures (2 mM cholesterol, $1 \mathrm{mM}$ oleic acid, and $2.4 \mathrm{mM}$ phosphatidylcholine) were dissolved in methanol and dried under nitrogen before adding $15 \mathrm{mM}$ PBS containing $6.6 \mathrm{mM}$ taurocholate salt, at $\mathrm{pH}$ 7.4. The suspension was sonicated twice for $30 \mathrm{~min}$ using a sonicator. The micelle solution was incubated overnight at $37{ }^{\circ} \mathrm{C}$. The extract or equivalent PBS as control were added to the mixed micelle solution and incubated for a further $2 \mathrm{~h}$ at $37^{\circ} \mathrm{C}$. The solution was then centrifuged at $16,000 \mathrm{rpm}$ for $20 \mathrm{~min}$. The supernatant was collected for the determination of cholesterol by using total cholesterol test kits. Gallic acid was used as a positive control.

\section{Bile acid binding}

The bile acid binding assay was done according to a previous method [17]. Taurocholic acid, glycodeoxycholic acid and taurodeoxycholic acid were used as bile acid in this experiment. Briefly, the extract $(1 \mathrm{mg} / \mathrm{mL})$ was incubated with each bile acid $(2 \mathrm{mM})$ containing in $0.1 \mathrm{M} \mathrm{PBS}, \mathrm{pH} 7$ at $37{ }^{\circ} \mathrm{C}$ for $90 \mathrm{~min}$. The mixtures were filtered through $0.2 \mu \mathrm{m}$ filter and the bile acid concentration was determined using a bile-acid analysis kit. Cholestyramine was used as a positive control in this study.

\section{Trolox equivalent antioxidant capacity (TEAC) assay}

The TEAC assay was performed according to a previous publication [14]. The absorbance was measured at 595 after incubation using a spectrophotometer. The TEAC value was calculated from a standard curve using a Trolox. The TEAC value was expressed as micromole of Trolox equivalents per milligram of extract.

\section{Oxygen radical absorbance capacity (ORAC) assay}

The ORAC assay was determined according to a previously described method by using 2,2'-azo-bis (2-amidinopropane) dihydrochloride (APPH), a free radical generator solution [14]. The fluorescence intensity at an excitation wavelength $485 \mathrm{~nm}$ and emission wavelength $535 \mathrm{~nm}$ was recorded every $2 \mathrm{~min}$ for $60 \mathrm{~min}$. A standard curve was generated with a Trolox concentration range from 0 to $48 \mu \mathrm{M}$. The ORAC value was calculated as the area under the curve (AUC) and expressed as micromole of Trolox equivalents per milligram of extract.

\section{Hydroxyl radical scavenging activity (HRSA)}

The HRSA was measured according to a previously described method by using the mixture of hydroxyl radical solution [14]. The absorbance was measured at $532 \mathrm{~nm}$. The HRSA value was calculated from a standard curve using a Trolox. The HRSA value was expressed as milligram of Trolox equivalents per milligram of extract.

\section{Superoxide radical scavenging activity (SRSA)}

The SRSA was measured according to a previously described publication by using the mixture of superoxide radical solution [14]. After incubation for $40 \mathrm{~min}$ at $37^{\circ} \mathrm{C}$, the absorbance was determined at $560 \mathrm{~nm}$. The SRSA value was calculated from a standard curve using a Trolox. The SRSA value was expressed as milligram of Trolox equivalents per milligram of extract.

\section{Statistical analysis}

Data were expressed as mean \pm standard error of the mean of three replicate determinations. Pearson's correlation analysis was used to determine the correlation between total phenolic content (TPC) and antioxidant activity, the percentage of inhibition of pancreatic lipase, and pancreatic cholesterol esterase (SPSS Statistics 17.0, SPSS Inc., Chicago, IL, USA). A value of $P<0.001$ was considered to be statistically significant.

\section{Results}

The results in Table 2 demonstrate the percentage inhibition of herbal medicines against the intestinal $\alpha$ glucosidases (maltase and sucrase) and pancreatic $\alpha$ amylase. At concentration of $1 \mathrm{mg} / \mathrm{mL}$, herbal medicines markedly inhibited intestinal maltase, ranging from 5.16-44.33 \%. Among eleven herbal extracts, Syzygium aromaticum and Schefflera leucantha were the highest and lowest effective intestinal maltase inhibitor, respectively. They slightly inhibited the intestinal sucrase with the percentage inhibition of $1.25-45.86 \%$. It was found that Phyllanthus amarus was the most effective inhibitor, whereas Cissus quadrangularis had the lowest potent intestinal sucrase inhibitor among those of extracts. It was noted that herbal medicines showed weak inhibition against pancreatic $\alpha$-amylase (1.75-12.53\%). Furthermore, acarbose $(0.005 \mathrm{mg} / \mathrm{mL})$ markedly inhibited intestinal maltase and sucrase with $64.87 \pm 0.32 \%$ and $11.42 \pm 2.49 \%$, respectively. At the concentration of $0.16 \mathrm{mg} / \mathrm{mL}$, acarbose had pancreatic $\alpha$-amylase inhibitory activity with $60.22 \pm 2.90 \%$. 
Table $2 \%$ Inhibition of herbal medicines (1 mg/mL) against pancreatic a-amylase, the intestinal a-glucosidase (maltase and sucrase), pancreatic lipase, and pancreatic cholesterol esterase

\begin{tabular}{|c|c|c|c|c|c|}
\hline \multirow[t]{2}{*}{ Plant samples } & \multicolumn{5}{|l|}{$\%$ Inhibition } \\
\hline & a-Pancreatic amylase & Maltase & Sucrase & Pancreatic lipase & Pancreatic cholesterol esterase \\
\hline Rhinacanthus nasutus & N.I. & $2.72 \pm 0.93$ & $6.10 \pm 1.43$ & $55.82 \pm 4.34$ & $15.06 \pm 0.56$ \\
\hline Cissus quadrangularis & $2.98 \pm 0.03$ & $7.50 \pm 1.12$ & $3.99 \pm 1.44$ & $21.42 \pm 4.36$ & $12.79 \pm 3.32$ \\
\hline Syzygium aromaticum & N.I & $44.33 \pm 2.96$ & $45.08 \pm 2.22$ & $85.93 \pm 0.53$ & $53.55 \pm 1.07$ \\
\hline Acanthus ebracteatus & N.I & $11.72 \pm 4.91$ & $2.69 \pm 0.41$ & $29.64 \pm 4.19$ & $2.92 \pm 1.05$ \\
\hline Thunbergia laurifolia & $11.40 \pm 2.58$ & $10.10 \pm 0.49$ & $16.62 \pm 3.11$ & $54.25 \pm 3.00$ & $25.39 \pm 2.42$ \\
\hline Phyllanthus amarus & $12.53 \pm 3.00$ & $38.25 \pm 0.60$ & $48.49 \pm 1.85$ & $65.30 \pm 0.47$ & $20.04 \pm 0.41$ \\
\hline Cassia alata & $6.80 \pm 2.63$ & $5.66 \pm 0.58$ & $1.25 \pm 0.49$ & $59.24 \pm 1.37$ & $18.14 \pm 1.55$ \\
\hline Pluchea indica & $12.04 \pm 1.80$ & $30.31 \pm 2.15$ & $1.84 \pm 0.20$ & $50.94 \pm 0.12$ & $12.76 \pm 1.46$ \\
\hline Cryptolepis buchanani & N.I. & $5.16 \pm 0.90$ & $4.30 \pm 1.02$ & $38.79 \pm 1.85$ & $24.72 \pm 1.91$ \\
\hline Derris scandens & $1.75 \pm 0.86$ & $8.09 \pm 0.87$ & $4.30 \pm 1.02$ & $51.48 \pm 0.26$ & $10.30 \pm 0.73$ \\
\hline Schefflera leucantha & N.I. & N.I. & $5.25 \pm 2.01$ & $38.51 \pm 1.50$ & $30.90 \pm 2.45$ \\
\hline Acarbose $^{a, b}$ & $60.22 \pm 2.90$ & $64.87 \pm 0.32$ & $11.42 \pm 2.49$ & - & - \\
\hline Orlistat $^{c}$ & - & - & - & $76.55 \pm 2.72$ & - \\
\hline Simvastatin $^{d}$ & - & - & - & - & $51.01 \pm 0.79$ \\
\hline
\end{tabular}

Results are represented as mean \pm SEM $(n=3)$. N.I. = No inhibition. ${ }^{a}$ Acarbose at concentration $0.16 \mathrm{mg} / \mathrm{mL}$ for pancreatic a-amylase inhibition and ${ }^{\mathrm{b}}$ acarbose at concentration $0.005 \mathrm{mg} / \mathrm{mL}$ for maltase and sucrase inhibition. ${ }^{c}$ Orlistst at concentration $0.063 \mathrm{mg} / \mathrm{mL}$. ${ }^{\mathrm{d}}$ Simvastatin at concentration $0.13 \mathrm{mg} / \mathrm{mL}$

The results of pancreatic lipase and cholesterol esterase inhibition by various herbal medicines $(1 \mathrm{mg} / \mathrm{mL})$ are summarized in Table 2 . A variety of the tested plant extracts showed a strong inhibitory potential against pancreatic lipase with ranging from 21.42 to $85.93 \%$. The extracts were further investigated for their pancreatic lipase inhibitory effects at different concentrations. The results showed that all extracts markedly inhibited pancreatic lipase activity in a concentration-dependent manner. As shown in Fig. 1, Syzygium aromaticum was the most effective pancreatic lipase inhibitor with $\mathrm{IC}_{50}$ values of $0.015 \pm 0.002 \mathrm{mg} / \mathrm{mL}$, whereas Cissus quadrangularis was the lowest potent inhibitor among those of the extracts $\left(\mathrm{IC}_{50}=4.259 \pm 0.131 \mathrm{mg} / \mathrm{mL}\right)$. However, all extracts were less potent than that of orlistat on inhibition of pancreatic lipase $\left(\mathrm{IC}_{50}=0.058 \pm 0.005 \mathrm{mg} / \mathrm{mL}\right)$.

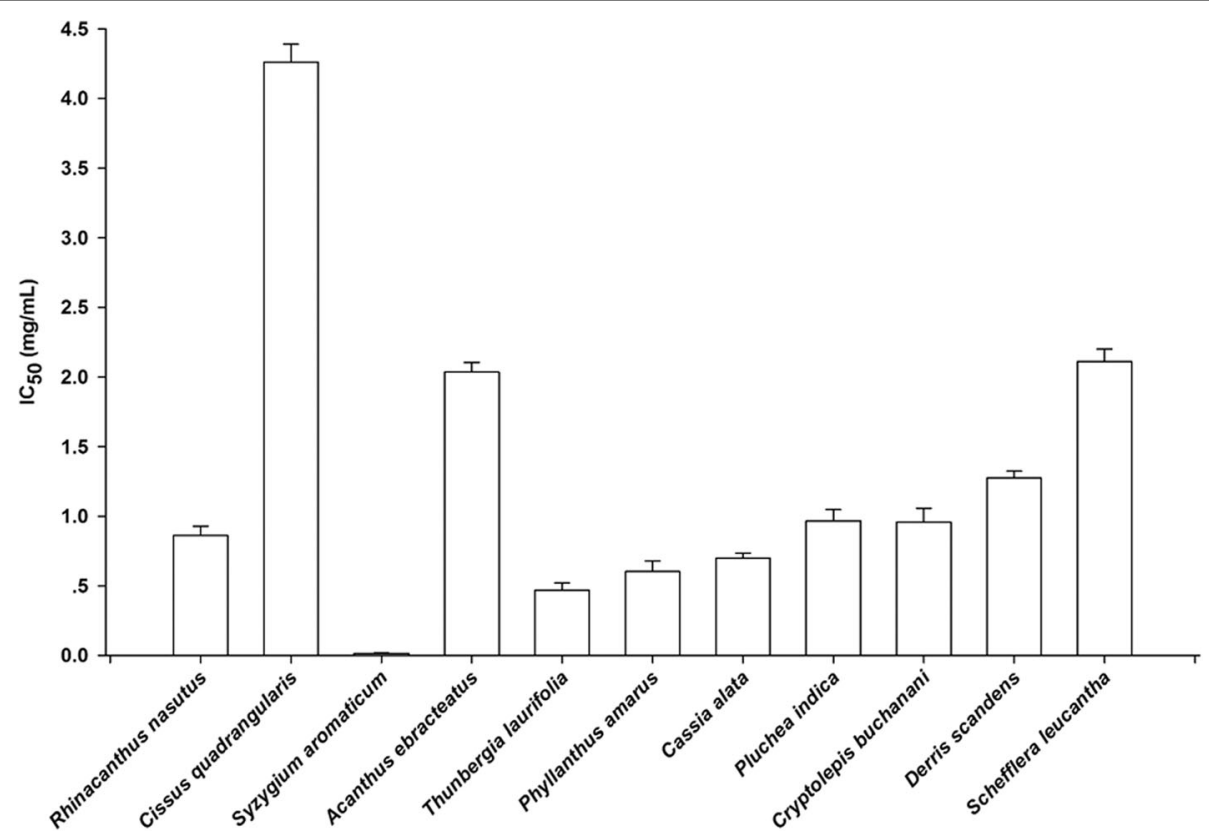

Fig. 1 The $I C_{50}$ values of herbal medicines against pancreatic lipase. The results are represented as mean $\pm \operatorname{SEM}(n=3)$ 
At concentration of $1 \mathrm{mg} / \mathrm{mL}$, Syzygium aromaticum markedly inhibited pancreatic cholesterol esterase activity with $53.35 \pm 1.07 \%$, whereas other herbal medicines attenuated this enzyme activity with the range of 2.92-30.9\%. In addition, simvastatin had the percentage inhibition of $51.01 \pm 0.79 \%$ at the concentration of $0.13 \mathrm{mg} / \mathrm{mL}$.

The results in Table 3 describe the percentage inhibition of herbal medicines $(1 \mathrm{mg} / \mathrm{mL})$ on cholesterol micellization. Syzygium aromaticum, Phyllanthus amarus, Rhinacanthus nasutus, and Thunbergia laurifolia slightly reduced the formation of cholesterol micellization with values of $2.29-33.74 \%$, whereas other herbal medicines had no inhibitory activity. Gallic acid $(0.06 \mathrm{mg} / \mathrm{mL})$ markedly inhibited the formation of cholesterol micelles about $32.48 \pm 3.33 \%$. The percentage of bile acid binding by herbal medicines $(1 \mathrm{mg} / \mathrm{mL})$ is shown in Table 3 . The results showed that Phyllanthus amarus demonstrated the highest binding of glycodeoxycholic acid and taurocholic acid with a degree of $15.08 \%$ and $18.40 \%$, respectively. The highest binding of taurodeoxycholic acid was observed with Syzygium aromaticum (18.18\%). Additionally, cholestyramine $(1 \mathrm{mg} / \mathrm{mL})$ bound $55.07 \pm 2.85 \%, 36.86 \pm$ $2.27 \%$, and $61.20 \pm 1.44 \%$ of glycodeoxycholic acid, taurocholic acid, and taurodeoxycholic acid, respectively.

Antioxidant activities of eleven herbal medicines are presented in Table 4. The results demonstrated that the extracts had various antioxidant activity including TEAC, ORAC, SRSA, and HRSA with the range of 0.50-4.70 $\mu \mathrm{mol}$ trolox/mg dried extract, 9.14-44.41 $\mu \mathrm{mol}$ trolox/mg dried extract, $0.31-18.82 \mathrm{mg}$ trolox $/ \mathrm{mg}$ dried extract, and 0.05-2.29 mg trolox/mg dried extract, respectively. Comparing with a previous study [14], it was found that the highest TEAC, ORAC, and SRSA were elicited by Syzygium aromaticum. It was observed that
Cissus quadrangularis had the highest SRSA in comparison with other herbal medicines.

The total phenolic content (TPC) of extracts was previously reported by our experiments [15] that have been used for the calculation of Pearson's correlation coefficients in the present study. The Pearson's correlation coefficients between the variables are presented in Table 5 . There were strong positive significant correlation between the contents of phenolic compounds and \% inhibition of pancreatic lipase $(r=0.885, p<0.001)$, \% inhibition of pancreatic cholesterol esterase $(r=0.761, p<0.001)$, and the TEAC value $(r=0.840, p<0.001)$. Furthermore, a strongly positive correlation was also found between the TEAC value and \% inhibition of pancreatic cholesterol esterase $(r=0.851, p<0.001)$ and $\%$ inhibition of pancreatic lipase $(r=0.755, p<0.001)$. In contrast, the negative correlation was observed between the HRSA and the SRSA value.

\section{Discussion}

Herbal medicines remain one of the most alternative approaches for the prevention and management of chronic degenerative diseases such as type 2 diabetes and cardiovascular diseases $[12,13]$. Consumption of carbohydrate and fat enriched foods causes a rapid rise in the blood glucose and lipid profiles. In this regards, inhibition of pancreatic $\alpha$-amylase and $\alpha$-glucosidase impedes the postprandial glucose excursion to enable overall smooth glucose profile. Recent evidence also supports that aggressive delaying dietary fat digestion and absorption is a new strategy for prevention of hyperlipidemia [18]. Inhibition of pancreatic lipase and pancreatic cholesterol esterase results in delaying the process of hydrolyzing dietary triglyceride and cholesterol esters, respectively $[19,20]$. In meantime, binding bile acids by forming

Table 3 The effect of herbal medicines $(1 \mathrm{mg} / \mathrm{mL}$ ) on inhibition of cholesterol micellization and bile acid binding

\begin{tabular}{|c|c|c|c|c|}
\hline \multirow[t]{2}{*}{ Plant samples } & \multicolumn{4}{|l|}{$\%$ Bile acid binding } \\
\hline & \% Cholesterol micellization inhibition & Glycodeoxycholic acid & Taurocholic acid & Taurodeoxycholic acid \\
\hline Rhinacanthus nasutus & $2.29 \pm 0.77$ & N.I. & N.I. & N.I. \\
\hline Cissus quadrangularis & N.I. & N.I. & N.I. & N.I. \\
\hline Syzygium aromaticum & $18.43 \pm 0.179$ & $13.47 \pm 1.41$ & $18.40 \pm 2.04$ & $18.18 \pm 1.74$ \\
\hline Acanthus ebracteatus & N.I. & N.I. & N.I. & N.I. \\
\hline Thunbergia laurifolia & $6.64 \pm 0.67$ & $9.90 \pm 1.01$ & $11.91 \pm 1.36$ & $12.55 \pm 2.34$ \\
\hline Phyllanthus amarus & $33.74 \pm 0.23$ & $15.08 \pm 1.44$ & $16.77 \pm 1.74$ & $13.36 \pm 4.51$ \\
\hline Cassia alata & N.I. & N.I. & N.I. & N.I. \\
\hline Pluchea indica & N.I. & N.I. & N.I. & N.I. \\
\hline Cryptolepis buchanani & N.I. & N.I. & N.I. & N.I. \\
\hline Derris scandens & N.I. & $2.05 \pm 0.27$ & $4.19 \pm 2.61$ & $5.70 \pm 0.39$ \\
\hline Schefflera leucantha & N.I. & N.I. & $1.76 \pm 0.75$ & $3.17 \pm 1.21$ \\
\hline Gallic acid (0.06 mg/mL) & $32.48 \pm 3.33$ & - & - & - \\
\hline Cholestyramine (1 mg/mL) & - & $55.07 \pm 2.58$ & $36.86 \pm 2.27$ & $61.20 \pm 1.44$ \\
\hline
\end{tabular}


Table 4 Antioxidant activity of herbal medicines including TEAC, ORAC, HRSA and SRSA

\begin{tabular}{lllll}
\hline Plant samples & Antioxidant activity & & & \\
\cline { 2 - 4 } & TEAC & ORAC & SRSA & HRSA \\
\hline Rhinacanthus nasutus & $0.92 \pm 0.01$ & $18.31 \pm 0.07$ & $5.31 \pm 0.45$ & $1.86 \pm 0.02$ \\
Cissus quadrangularis & $0.52 \pm 0.01$ & $9.14 \pm 0.05$ & $0.31 \pm 0.03$ & $2.29 \pm 0.05$ \\
Syzygium aromaticum & $4.70 \pm 0.03^{\mathrm{a}}$ & $31.21 \pm 0.21^{\mathrm{a}}$ & $18.82 \pm 0.50^{\mathrm{a}}$ & $0.15 \pm 0.04^{\mathrm{a}}$ \\
Acanthus ebracteatus & $0.50 \pm 0.01$ & $10.77 \pm 0.23$ & $9.47 \pm 0.39$ & $0.38 \pm 0.01$ \\
Thunbergia laurifolia & $1.07 \pm 0.01$ & $44.41 \pm 0.53$ & $14.39 \pm 0.24$ & $1.48 \pm 0.08$ \\
Phyllanthus amarus & $1.40 \pm 0.01$ & $19.70 \pm 0.17$ & $15.77 \pm 0.45$ & $0.06 \pm 0.02$ \\
Cassia alata & $0.69 \pm 0.01$ & $14.63 \pm 0.13$ & $4.89 \pm 0.31$ & $1.15 \pm 0.04$ \\
Pluchea indica & $1.61 \pm 0.01$ & $28.06 \pm 0.19$ & $19.38 \pm 0.50$ & $0.05 \pm 0.01$ \\
Cryptolepis buchanani & $1.01 \pm 0.01$ & $21.22 \pm 0.05$ & $10.30 \pm 0.18$ & $1.14 \pm 0.01$ \\
Derris scandens & $1.38 \pm 0.01$ & $18.21 \pm 0.23$ & $7.32 \pm 0.24$ & $1.46 \pm 0.01$ \\
Schefflera leucantha & $0.86 \pm 0.02$ & $19.61 \pm 0.44$ & $7.80 \pm 0.42$ & $0.59 \pm 0.02$ \\
\hline Da ara
\end{tabular}

Data are expressed as mean \pm S.E.M, $n=3$. TEAC was expressed as micromole trolox/ $\mathrm{mg}$ dried extract. ORAC was expressed as micromole trolox/ mg dried extract. Hydroxyl radical scavenging activity (HRSA) was expressed as milligram trolox/mg dried extract. Superoxide radical scavenging activity (SRSA) was expressed as milligram trolox/mg dried extract. a antioxidant activity of Syzygium aromaticum was previously reported by our publication [62]

insoluble complexes and increasing their fecal excretion as well as the reduction of micelle formation have been referred to as possible mechanisms for lowering blood cholesterol level [21]. Additionally, postprandial oxidative stress has been linked with consumption of a meal rich in lipids and/or carbohydrates [22]. The present findings are important, particularly in view of antihyperglycemic and antihyperlipidemic mechanisms of eleven herbal medicines including the intestinal $\alpha$-glucosidase, pancreatic $\alpha$-amylase, pancreatic lipase and pancreatic cholesterol esterase inhibitory activities as well as bile acid binding and the inhibition of cholesterol micellization. Furthermore, the medicinal properties of the plants have been explored for their potential antioxidant. Among the plant extracts examined, three herbal medicines exhibit a high potential for antihyperglycemic and antihyperlipidemic activity including Syzygium aromaticum, Thunbergia laurifolia and Phyllanthus amarus.

Table 5 Pearson's correlation analyses of total phenolic content (TPC), \% inhibition of pancreatic lipase (PL) $(1 \mathrm{mg} / \mathrm{mL}), \%$ inhibition of pancreatic cholesterol esterase (Chol) $(1 \mathrm{mg} / \mathrm{mL})$, ORAC, TEAC, SRSA, and HRSA

\begin{tabular}{llllllll}
\hline & TPC & PL & Chol & ORAC & TEAC & SRSA & HRSA \\
\hline TPC & - & $0.885^{*}$ & $0.761^{*}$ & 0.386 & $0.840^{*}$ & 0.594 & -0.441 \\
PL & - & - & 0.643 & 0.547 & $0.755^{*}$ & 0.648 & -0.454 \\
Chol & - & - & - & 0.490 & $0.851^{*}$ & 0.389 & -0.197 \\
ORAC & - & - & - & - & 0.459 & 0.698 & -0.203 \\
TEAC & - & - & - & - & - & 0.642 & -0.457 \\
SRSA & - & - & - & - & - & - & $-0.785^{*}$ \\
HRSA & - & - & - & - & - & - & - \\
\hline
\end{tabular}

"Correlation is significant at $P<0.001$
There are several reports demonstrating antihyperglycemic and antihyperlipidemic activity of three herbal medicines. For example, clove (Syzygium aromaticum) bud powder reduced blood glucose level in a high fatinduced diabetic rat [23]. A previous study revealed that eugeniin, the phytochemical compounds isolated from aqueous methanol extraction was attributed with the inhibition of rat intestinal maltase [24]. The present investigation evaluated the inhibitory activity of pancreatic $\alpha$-amylase and $\alpha$-glucosidase by using water-solvent extraction. The extraction method differs from previous studies which may result in various biological activities. Syzygium spp-derived triterpenes oleanolic acid (OA) and maslinic acid (MA) ameliorated postprandial hyperglycemia in diabetic rats through the inhibition of intestinal $\alpha$-glucosidase and $\alpha$-amylase [25]. OA have been reported to inhibit $\alpha$-glucosidase as uncompetitive inhibition. The inhibitory activity of OA may be due to the triterpenoid structure [26]. The aqueous extract of Syzygium aromaticum also inhibited fructose-induced protein glycation and oxidation [14]. Furthermore, the ethanolic extract of Syzygium aromaticum markedly reduced serum triglyceride and cholesterol in high-fat diet-induced obese mice through downregulation of adipogenic and lipogenic gene expression [27]. However, other mechanisms of antihyperlipidemic activity of Syzygium aromaticum have not been described. The methanolic extract of Phyllanthus amarus was reported to have hypoglycemic effect on alloxaninduced diabetic rats [28]. In addition, significant alterations in lipid profiles were attenuated in diabetic rats treated with Phyllanthus amarus aqueous extract [29]. Moreover, the 15-day-treatment of Thunbergia laurifolia decreased plasma glucose concentration in diabetic rats 
[30]. Taken together, the present findings might describe antihyperglycemic and antihyperlipidemic mechanisms of three herbal medicines in diabetic rats.

Several reports support that total phenolic compounds in the herbal medicines have the ability to inhibit pancreatic $\alpha$-amylase, $\alpha$-glucosidase, pancreatic lipase activity and pancreatic cholesterol esterase $[12,31]$ whereas they reduce the formation of cholesterol micelles and bile acid binding [31, 32]. Other studies published earlier also showed positive correlation between phenolic compounds and the antioxidant activity of plant extracts and pancreatic lipase inhibitory activity [33]. The present results demonstrate a significant positive correlation between phenolic contents and pancreatic lipase inhibition activity, pancreatic cholesterol esterase, and antioxidant activity (TEAC) which provide strong support that phenolic compounds are key agents for pancreatic lipase and pancreatic cholesterol esterase inhibition as well as antioxidant activity.

\section{Conclusions}

Eleven herbal medicines markedly demonstrated antioxidant, antihyperglycemic, and antihyperlipidemic activities, in particular, Syzygium aromaticum, Thunbergia laurifolia and Phyllanthus amarus. Interestingly, the phenolic compounds in the promising herbal medicines exhibited strong correlation to the inhibitory activity against pancreatic lipase, pancreatic cholesterol esterase, and the TEAC values. These results indicate that these herbal medicines could be a natural source for antioxidant, antihyperglycemic, and antihyperlipidemic agents.

\section{Abbreviations \\ Chol: pancreatic cholesterol esterase; HRSA: Hydroxyl radical scavenging activity; ORAC: Oxygen radical absorbance capacity; PL: Pancreatic lipase; SRSA: Superoxide radical scavenging activity; TEAC: Trolox equivalent antioxidant capacity \\ Funding \\ This research was supported by Government Research Budget, Thailand and Grant for International Research Integration: Chula Research Scholar, Ratchadaphiseksomphot Endowment Fund, Chulalongkorn University and Ratchadapisek Sompote Fund for Postdoctoral Fellowship, Chulalongkorn University.}

\section{Availability of data and materials}

Data are all contained within the paper.

\section{Authors' contributions}

WS, TS, NM, AK, CM, CA, and TT were responsible for the experiments, acquisition of data, analysis, and interpretation of data. SA has made substantial contributions to conception and design, drafted the manuscript and revised it critically for important intellectual content. All authors conducted to the drafting of the manuscript and agreed on the final approval of the version to be published.

\section{Competing interests}

The authors declare that they have no competing interests.

Consent for publication

Not applicable.
Ethic approval and consent to participate

Not applicable.

\section{Author details}

${ }^{1}$ Department of Nutrition and Dietetics, Faculty of Allied Health Sciences, Chulalongkorn University, Bangkok 10330, Thailand. ${ }^{2}$ Program in Nutrition and Dietetics, Department of Nutrition and Dietetics, Faculty of Allied Health Sciences, Chulalongkorn University, Bangkok 10330, Thailand. ${ }^{3}$ Program in Biomedical Sciences, Graduate School, Chulalongkorn University, Bangkok 10330, Thailand

Received: 29 June 2016 Accepted: 18 October 2016

Published online: 04 November 2016

\section{References}

1. Ogden CL, Carroll MD, Curtin LR, McDowell MA, Tabak CJ, Flegal KM. 370 Prevalence of overweight and obesity in the United States, 1999-2004. JAMA. 2006;295:1549-55.

2. Wong JM, Jenkins DJ. Carbohydrate digestibility and metabolic effects. J Nutr. 2007;137(11 Supp):2539S-46S.

3. Tucci SA, Boyland EJ, Halford JC. The role of lipid and carbohydrate digestive enzyme inhibitors in the management of obesity: a review of current and emerging therapeutic agents. Diabetes Metab Syndr Obes. 2010;3:125-43.

4. Bonora E, Muggeo M. Postprandrialblood glucose as risk factor for cardiovascular disease in type II diabetes: the epidemiological evidence. Diabetologia. 2001;44:2107-14.

5. Enkhmaa B, Ozturk Z, Anuurad E, Berglund L. Postprandrail lipoproteins and cardiovascular disease in diabetes mellitus. Curr Diab Rep. 2010;10:61-9.

6. Gregersen S, Samocha-Bonet D, Heilbronn LK, Campbell LV. Inflammatory and oxidative stress responses to high-carbohydrate and high-fat meals in healthy humans. J Nutr Metab. 2012;2012:238056.

7. Van De Laar FA, Lucassen PL, Akkermans RP, Van De Lisdonk EH, Rutten GE, Van Weel C. a-glucosidase inhibitors for patients with type 2 diabetes results from a cochrane systematic review and meta-analysis. Diabetes Care. 2005;28:154-63

8. Drew BS, Dixon AF, Dixon JB. Obesity management: update on orlistat. Vasc Health Risk Manag. 2007;3:817.

9. Liao Y, Takashima S, Zhao H, Asano Y, Shintani Y, Minamino T, Kim J, Fujita M, Hori M, Kitakaze M. Control of plasma glucose with alpha-glucosidase inhibitor attenuates oxidative stress and slows the progression of heart failure in mice. Cardiovasc Res. 2006;70:107-16.

10. Bray GA, Greenway FL. Current and potential drugs for treatment of obesity. Endocr Rev. 1999;20:805-75.

11. Vichayanrat A, Ploybutr S, Tunlakit M, Watanakejorn P. Efficacy and safety of voglibose in comparison with acarbose in type 2 diabetic patients. Diabetes Res Clin Pract. 2002;55:99-103.

12. Önal S, Timur S, Okutucu B, Zihnioğlu F. Inhibition of a-glucosidase by aqueous extracts of some potent antidiabetic medicinal herbs. Prep Biochem Biotech. 2005;35:29-36.

13. Seyedan A, Alshawsh MA, Alshagga MA, Koosha S, Mohamed Z. Medicinal plants and their inhibitory activities against pancreatic lipase: A Review. Evid Based Complement Alternat Med. 2015;2015:973143.

14. Suantawee T, Wesarachanon K, Anantsuphasak K, Daenphetploy T, ThienNgern S, Thilavech T, Pasukamonset P, Ngamukote S, Adisakwattana S. Protein glycation inhibitory activity and antioxidant capacity of clove extract. J Food Sci Technol. 2015;52:3843-50.

15. Sompong W, Adisakwattana S. Inhibitory effect of herbal medicines and their trapping abilities against methylglyoxal-derived advanced glycation end-products. BMC Complement Alter Med. 2015;15:394.

16. Adisakwattana S, Ruengsamran T, Kampa P, Sompong W. In vitro inhibitory effects of plant-based foods and their combinations on intestinal alphaglucosidase and pancreatic alpha-amylase. BMC Complement Altern Med. 2012:12:110.

17. Mäkynen K, Jitsaardkul S, Tachasamran P, Sakai N, Puranachoti S, Nirojsinlapachai N, Chattapat V, Caengprasath N, Ngamukote S, Adisakwattana S. Cultivar variations in antioxidant and antihyperlipidemic properties of pomelo pulp (Citrus grandis [L.] Osbeck) in Thailand. Food Chem. 2013;139:735-43.

18. Ros E. Intestinal absorption of triglyceride and cholesterol. Dietary and pharmacological inhibition to reduce cardiovascular risk. Atherosclerosis. 2000;151:357-79. 
19. Birari RB, Bhutani KK. Pancreatic lipase inhibitors from natural sources: unexplored potential. Drug Discov Today. 2007;12:879-89.

20. Brodt-Eppley J, White P, Jenkins S, Hui DY. Plasma cholesterol esterase level is a determinant for an atherogenic lipoprotein profile in normolipidemic human subjects. Biochim Biophys Acta. 1995;1272:69-72.

21. van Bennekum AM, Nguyen DV, Schulthess G, Hauser H, Phillips MC. Mechanisms of cholesterol-lowering effects of dietary insoluble fibres: relationships with intestinal and hepatic cholesterol parameters. $\mathrm{Br} J$ Nutr. 2005;94:331-7.

22. Sies H, Stahl W, Sevanian A. Nutritional, dietary and postprandial oxidative stress. J Nutr. 2005;135:969-72.

23. Adefegha SA, Oboh G, Adefegha OM, Boligon AA, Athayde ML. Antihyperglycemic, hypolipidemic, hepatoprotective and antioxidative effects of dietary clove (Szyzgium aromaticum) bud powder in a high-fat diet/ streptozotocin-induced diabetes rat model. J Sci Food Agr. 2014;94:2726-37.

24. Toda M, Kawabata J, Kasai T. Alpha-glucosidase inhibitors from clove (Syzgium aromaticum). Biosci Biotechnol Biochem. 2000;64:294-8.

25. Khathi A, Serumula MR, Myburg RB, Van Heerden FR, Musabayane CT. Effects of Syzygium aromaticum-derived triterpenes on postprandial blood glucose in streptozotocin-induced diabetic rats following carbohydrate challenge. PLoS ONE. 2013;8:e81632.

26. Castellano JM, Guinda A, Delgado T, Rada M, Cayuela JA. Biochemical basis of the antidiabetic activity of oleanolic acid and related pentacyclic triterpenes. Diabetes. 2013;62:1791-9.

27. Jung $\mathrm{CH}$, Ahn J, Jeon TI, Kim TW, Ha TY. Syzygium aromaticum ethanol extract reduces high-fat diet-induced obesity in mice through downregulation of adipogenic and lipogenic gene expression. Exp Ther Med. 2012;4:409-14.

28. Raphael KR, Sabu MC, Kuttan R. Hypoglycemic effect of methanol extract of Phyllanthus amarus Schum \& Thonn on alloxan induced diabetes mellitus in rats and its relation with antioxidant potential. Indian J Exp Biol. 2002;40:905-9.

29. Karuna R, Bharathi VG, Reddy SS, Ramesh B, Saralakumari D. Protective effects of Phyllanthus amarus aqueous extract against renal oxidative stress in Streptozotocin-induced diabetic rats. Indian J Pharmacol. 2011;43:414.

30. Aritajat S, Wutteerapol S, Saenphet K. Anti-diabetic effect of Thunbergia laurifolia Linn. Aqueous extract. Southeast Asian J Trop Med Public Health. 2004:35 Suppl 2:53-8.

31. Adisakwattana S, Intrawangso J, Hemrid A, Chanathong B, Mäkynen K. Extracts of edible plants inhibit pancreatic lipase, cholesterol esterase and cholesterol micellization, and bind bile acids. Food Technol Biotech. 2012;50:11-6.

32. Ngamukote S, Mäkynen K, Thilawech T, Adisakwattana S. Cholesterollowering activity of the major polyphenols in grape seed. Molecules. 2011;16:5054-61.

33. Dechakhamphu A, Wongchum N. Screening for anti-pancreatic lipase properties of 28 traditional Thai medicinal herbs. Asian Pac J Trop Biomed. 2015;5:1042-5

34. Gotoh A, Sakaeda T, Kimura T, Shirakawa T, Wada Y, Wada A, Kimachi T, Takemoto Y, lida A, Iwakawa S, et al. Antiproliferative activity of Rhinacanthus nasutus (L.) Kurz extracts and the active moiety, Rhinacanthin C. Biol Pharm Bull. 2004;27:1070-4.

35. Visweswara Rao P, Madhavi K, Dhananjaya Naidu M, Gan SH. Rhinacanthus nasutus improves the levels of liver carbohydrate, protein, glycogen, and liver markers in streptozotocin-induced diabetic rats. Evid Based Complement Alternat Med. 2013;2013:102901.

36. Prajuabjinda O, Panthong S, Itharat A. Antimicrobial activity of Thai medicinal preparation of Khampramong Temple used for cancer treatment and its plant components. J Med Assoc Thai. 2012;95 Suppl 1:S159-65.

37. Lekshmi R, Sreekutty M, Mini $\mathrm{S}$. The regulatory effects of Cissus quadrangularis on some enzymes involved in carbohydrate metabolism in streptozotocininduced diabetic rats. Pharma Biol. 2015:53:1194-200.

38. Swamy AH, Kulkarni RV, Koti BC, Gadad PC, Thippeswamy AH, Gore A. Hepatoprotective effect of Cissus quadrangularis stem extract against rifampicin-induced hepatotoxicity in rats. Indian J Pharm Sci. 2012;74:183-7.

39. Oben JE, Ngondi JL, Momo CN, Agbor GA, Sobgui CS. The use of a Cissus quadrangularis/IIvingia gabonensis combination in the management of weight loss: a double-blind placebo-controlled study. Lipids Health Dis. 2008;7:12.

40. Banu J, Varela E, Bahadur AN, Soomro R, Kazi N, Fernandes G. Inhibition of bone loss by Cissus quadrangularis in mice. A preliminary repor. J Osteoporos. 2012;2012:101206.

41. Nm J, Rm R, G G, Maliakel B, D S, Im K. Beyond the flavour: a de-flavoured polyphenol rich extract of clove buds (Syzygium aromaticum $\mathrm{L}$ ) as a novel dietary antioxidant ingredient. Food Funct. 2015;6:3373-82
42. Issac A, Gopakumar G, Kuttan R, Maliakel B, Krishnakumar IM. Safety and anti-ulcerogenic activity of a novel polyphenol-rich extract of clove buds (Syzygium aromaticum L). Food Funct. 2015;6:842-52.

43. Dibazar SP, Fateh S, Daneshmandi S. Immunomodulatory effects of clove (Syzygium aromaticum) constituents on macrophages: in vitro evaluations of aqueous and ethanolic components. J Immunotoxicol. 2015;12:124-31.

44. Kumar PS, Febriyanti RM, Sofyan FF, Luftimas DE, Abdulah R. Anticancer potential of Syzygium aromaticum L. in MCF-7 human breast cancer cell lines. Pharmacognosy Res. 2014;6:350-4.

45. Sittiwet C, Niamsa N, Puangpronpitag D. Antimicrobial activity of Acanthus ebracteatus Vahl. Aqueous extract: the potential for skin infection treatment. Int J Biol Chem. 2009;3:95-8.

46. Mahasiripanth T, Hokputsa S, Niruthisard S, Bhattarakosol P, Patumraj S. Effects of Acanthus ebracteatus Vahl on tumor angiogenesis and on tumor growth in nude mice implanted with cervical cancer. Cancer Manag Res. 2012:4:269-79.

47. Boonyarikpunchai W, Sukrong S, Towiwat P. Antinociceptive and antiinflammatory effects of rosmarinic acid isolated from Thunbergia laurifolia Lindl. Pharmacol Biochem Behav. 2014;124:67-73.

48. Junsi M, Siripongvutikorn S. Thunbergia laurifolia, a traditional herbal tea of Thailand: botanical, chemical composition, biological properties and processing influence. Int Food Res J. 2016;23:923-7.

49. Saenphet K, Kantaoop P, Saenphet S, Aritajat S. Mutagenicity of Pueraria mirifica Airy Shaw \& Suvatabandhu and antimutagenicity of Thunbergia laurifolia Linn. Southeast Asian J Trop Med Public Health. 2005;36 Suppl 4:238-41.

50. Pramyothin $\mathrm{P}$, Chirdchupunsare $\mathrm{H}$, Rungsipipat A, Chaichantipyuth C. Hepatoprotective activity of Thunbergia laurifolia Linn extract in rats treated with ethanol: in vitro and in vivo studies. J Ethnopharmacol. 2005;102:408-11.

51. Ali H, Houghton PJ, Soumyanath A. a-Amylase inhibitory activity of some Malaysian plants used to treat diabetes; with particular reference to Phyllanthus amarus. J Ethnopharmacol. 2006;107:449-55.

52. Ilangkovan M, Jantan I, Mesaik MA, Bukhari SN. Immunosuppressive effects of the standardized extract of Phyllanthus amarus on cellular immune responses in Wistar-Kyoto rats. Drug Des Devel Ther. 2015;9:4917-30.

53. Adedapo AA, Ofuegbe SO. Anti-inflammatory and antinociceptive activities of the aqueous leaf extract of Phyllanthus amarus Schum (Euphorbiaceae) in some laboratory animals. J Basic Clin Physiol Pharmacol. 2015;26:89-94.

54. Roengrit T, Wannanon P, Prasertsri P, Kanpetta Y, Sripanidkulchai BO, Leelayuwat N. Antioxidant and anti-nociceptive effects of Phyllanthus amarus on improving exercise recovery in sedentary men: a randomized crossover (double-blind) design. J Int Soc Sports Nutr. 2014;11:9.

55. Somchit MN, Reezal I, Nur IE, Mutalib AR. In vitro antimicrobial activity of ethanol and water extracts of Cassia alata. J Ethnopharmacol. 2003;84:1-4

56. Sagnia B, Fedeli D, Casetti R, Montesano C, Falcioni G, Colizzi V. Antioxidant and anti-inflammatory activities of extracts from Cassia alata, Eleusine indica, Eremomastax speciosa, Carica papaya and Polyscias fulva medicinal plants collected in Cameroon. PLoS ONE. 2014;9(8):e103999.

57. Buapool D, Mongkol N, Chantimal J, Roytrakul S, Srisook E, Srisook K. Molecular mechanism of anti-inflammatory activity of Pluchea indica leaves in macrophages RAW 264.7 and its action in animal models of inflammation. J Ethnopharmacol. 2013;146:495-504.

58. Mohamad S, Zin NM, Wahab HA, Ibrahim P, Sulaiman SF, Zahariluddin AS, Noor SS. Antituberculosis potential of some ethnobotanically selected Malaysian plants. J Ethnopharmacol. 2011;133:1021-6.

59. Sen T, Ghosh TK, Chaudhuri AK. Studies on the mechanism of antiinflammatory and anti-ulcer activity of Pluchea indica-probable involvement of 5-lipooxygenase pathway. Life Sci. 1993;52:737-43.

60. Hanprasertpong N, Teekachunhatean S, Chaiwongsa R, Ongchai S, Kunanusorn P, Sangdee C, Panthong A, Bunteang S, Nathasaen N, Reutrakul V. Analgesic, anti-inflammatory, and chondroprotective activities of Cryptolepis buchanani extract: in vitro and in vivo studies. Biomed Res Int. 2014;2014:978582.

61. Laupattarakasem P, Houghton PJ, Hoult JR. Anti-inflammatory isoflavonoids from the stems of Derris scandens. Planta Med. 2004;70:496-501.

62. Rao SA, Srinivas PV, Tiwari AK, Vanka UM, Rao RV, Dasari KR, Rao MJ. Isolation, characterization and chemobiological quantification of alphaglucosidase enzyme inhibitory and free radical scavenging constituents from Derris scandens Benth. J Chromatogr B Analyt Technol Biomed Life Sci. 2007:855:166-72.

63. Potduang B, Chongsiriroeg C, Benmart Y, Giwanon R, Supatanakul W, Tanpanich S. Biological activities of Schefflera leucantha. Afr J Tradit Complement Altern Med. 2006;4:157-64. 